\title{
THE
}

\section{Factors Predicting Civic Engagement Among Older Adult Nursing Home Residents}

Skye N. Leedahl

University of Rhode Island, skyeleedahl@uri.edu

Alicia Sellon

Naomi Gallopyn

Follow this and additional works at: https://digitalcommons.uri.edu/hdf_facpubs

The University of Rhode Island Faculty have made this article openly available.

Please let us know how Open Access to this research benefits you.

This is a pre-publication author manuscript of the final, published article.

Terms of Use

This article is made available under the terms and conditions applicable towards Open Access Policy Articles, as set forth in our Terms of Use.

\section{Citation/Publisher Attribution}

Skye N. Leedahl, Alicia M. Sellon \& Naomi Gallopyn (2017) Factors Predicting Civic Engagement among Older Adult Nursing Home Residents, Activities, Adaptation \& Aging, 41:3, 197-219, DOI: 10.1080/ 01924788.2017.1310581

Available at: http://dx.doi.org/10.1080/01924788.2017.1310581

This Article is brought to you for free and open access by the Human Development and Family Science at DigitalCommons@URI. It has been accepted for inclusion in Human Development and Family Science Faculty Publications by an authorized administrator of DigitalCommons@URI. For more information, please contact digitalcommons-group@uri.edu. 


\title{
Factors Predicting Civic Engagement Among Older Adult Nursing Home Residents
}

\author{
Skye N. Leedahl, PhD \\ University of Rhode Island \\ Departments of Human Development \& Family Studies and Political Science \\ Kingston, RI \\ skyeleedahl@uri.edu \\ Alicia M. Sellon, MSW \\ University of Kansas \\ School of Social Welfare \\ Center for Research on Aging and Disability Options \\ Lawrence, KS \\ aliciasellon@ku.edu \\ $\&$ \\ Naomi Gallopyn, BS \\ University of Massachusetts-Boston \\ Department of Gerontology \\ Boston, MA \\ naomi.gallopyn001@umb.edu
}

Journal: Activities, Adaptation, and Aging 


\begin{abstract}
This study examined civic engagement participation among older adult nursing home residents and determined resident characteristics that predict group membership, resident council participation, informal volunteering, and voting. Residents $(N=139)$ answered questions from standardized surveys during in-person interviews. The most common civic engagement activity was membership in social/community groups. Logistic regression results showed that emotional well-being and social support predict group membership and resident council participation. Age and activities of daily living predict volunteering. Study findings suggest that community groups could utilize residents in their efforts, and that future research should determine supports and adaptations for increasing civic engagement among residents.
\end{abstract}

Keywords: civic engagement, group membership, resident council, volunteering, voting 
Despite being recognized as a potential way to improve the health and well-being of older adults, participation in civic engagement activities has almost exclusively been the domain of healthy, community-dwelling older adults. Older adults who have moved from the community to nursing homes are less likely to have opportunities to participate in civic engagement activities and have largely been ignored in studies of civic engagement. However, nursing home residents could benefit from participation in a variety of civic engagement activities (Anderson \& Dabelko-Schoeny, 2010).

For this study, civic engagement for older adults broadly includes involvement in "activities of personal and public concern that are both individually life-enriching and socially beneficial to the community" (Cullinane, 2006, p. 66). Civic engagement has been defined within different realms, including as a community service, collective action, political involvement, and social change (Adler \& Goggin, 2005). Civic engagement can include a wide range of activities, including intensive volunteer activities (e.g., SeniorCorps); informal volunteering (e.g., helping at a charity; helping neighbors and friends); voting and other political activities (e.g., campaigning, participating in a political event); participation in neighborhood or community groups and events; and teaching or participating in educational activities (Adler \& Goggin, 2005).

One well-researched area of civic engagement research is related to volunteering and its benefits to communities and older adults. Volunteerism within the civic engagement literature tends to be divided into two types: formal and informal. Formal volunteering tends to be defined as participation in activities structured by an organization, with little or no compensation. Informal volunteering often includes taking on a helping role and providing support to family, friends, and neighbors (Cnaan, Handy, \& Wadsworth, 1996; Morrow-Howell, 2010). Older 
adults in nursing homes may participate in both forms of volunteerism, but this has not been previously studied.

Formal volunteering has been associated with both physical and mental health benefits (Greenfield \& Marks, 2004; Harris \& Thoresen, 2005; Lum \& Lightfoot, 2005; Martinez et al., 2006). Participation can also provide important opportunities for older adults to increase their social networks and interactions with their community, and it can give older adults the opportunity to engage in meaningful activities that can generate a sense of purpose and fulfillment (Martinez et al., 2006; Morrow-Howell, Hong, \& Tang, 2009; Mui, Glajchen, Chen, $\&$ Sun, 2013). Concerns have been raised, however, about characterizing civic engagement activities based exclusively on formal volunteer contributions (Martinez, Crooks, Kim, \& Tanner, 2011). Specifically, it has been suggested that informal volunteering and participation in community events have tended to be overlooked and undervalued. Increasingly more researchers are expanding the dialogue and conducting research to examine the informal contributions of older adults (e.g., Martinez et al., 2011).

In the existing literature, studies have tended to focus on the health benefits of volunteering for healthy, community-dwelling older adults with higher socioeconomic status (Martinez et al., 2011). Yet, participation in civic engagement activities may also be beneficial to those with cognitive or physical limitations (Dabelko-Schoeny, Anderson, \& Spinks, 2010) as well as minority and low-income older adults (Martinez et al., 2011). Indeed, Anderson \& Dabelko-Schoeny (2010) argue that there is a critical need for research that specifically targets civic engagement opportunities and participation for nursing home residents. This article seeks to address this gap in the literature by providing novel information about nursing home residents' participation in a variety of civic engagement activities and the predictors of their involvement. 


\section{Theoretical Framework}

Nursing home residents are often thought to be disengaged from the community and to be recipients of service. However, some residents may want and be able to engage in activities that are personally meaningful and could improve the community within and outside the nursing home. Activity and role theory can help understand the potential importance of participation in civic engagement activities for nursing home residents.

\section{Activity and Role Theories}

Some nursing home residents may be physically able and interested in participating in civic engagement activities. Generally associated with studies of community-dwelling older adults, activity theory holds promise as a framework for exploring activity and engagement among nursing home residents. Activity theory was one of the first gerontological theories developed to explain individual aging related to socialization (Havighurst and Albrecht, 1953). This theory posits that older adults who continue the roles and activities they have developed over their life course are more likely to be satisfied with their lives (Estes, 2001). Activity theory contradicts disengagement theory, which presumes that old age is a period when older adults and society become mutually disconnected, thus reducing the number of social connections older adults have (Estes, 2001; Hooyman \& Kiyak, 2011). Though some may continue to view old age in line with disengagement theory, activity theory helps shape current policy agendas that emphasize "successful aging" (Bowling, 2007), "healthy aging” (White House Conference on Aging, 2015), “active ageing" (World Health Organization, 2015), and "civic engagement" (O’Neill, 2006-2007), and it continues to be referenced as a guiding theory for research (e.g., Johnson, Whitlach, \& Menne, 2014; Dai, Zhang, \& Li, 2013). Therefore, it may serve as a useful 
lens for thinking about engaging nursing home residents in a variety of civic engagement activities.

Two related theories, role identity theory and continuity theory, have been used in research on social integration for older adults, mostly in social work (e.g., Gammonley, 2009; Rice, 1989; Siebert, Mutran, \& Reitzes, 1999) and sociology (e.g., Finchum \& Weber, 2000). The basic premise behind these theories is that older adults thrive when they continue to identify with specific roles (e.g., being a mother) or life events (e.g., living through the Great Depression) that have been especially important to them (Siebert, et al., 1999). As articulated by Turner (1978), a variety of roles are available to individuals throughout their lives. Some of these roles are central to a person's identity, while others are of lesser importance. Roles can provide a sense of meaning and purpose; however, as individuals age, opportunities to maintain those important roles may be reduced. Participation in civic engagement activities can provide a counter for role losses. Research suggests that participation in civic engagement activities, particularly volunteerism, can help older adults maintain previous role identities and/or develop new roles that provide them with a sense of purpose and contribute to their overall well-being (Greenfield \& Marks, 2004; Kaskie, Imhof, Cavanaugh, \& Culp, 2008; Morrow-Howell, Hinterlong, Rozario, \& Tang, 2003).

\section{Literature Review}

While there is a robust literature on predictors of participation in civic engagement activities for community-dwelling older adults, far less is known about predictors of involvement for institutionalized older adults. However, the existing literature does provide a valuable starting point in framing our discussion of key predictors of civic engagement by older adult nursing home residents. For the purposes of this study, civic engagement is operationalized as 
community/social group membership, participation in resident council, volunteering within the facility, and voting in a recent election. While we recognize potential overlap between these four categories of civic engagement, they are included separately in our analysis, as this provides a more comprehensive picture of this understudied area of research. Literature pertaining to key predictors of civic engagement and these four areas of research will be reviewed.

\section{Predictors of Participation}

Previous research suggests that gender, age, education level, and physical and mental health status are key predictors of civic engagement, particularly formal volunteerism (Adler, Schwartz, \& Kuskoski, 2007; Choi, 2003; Gottlieb \& Gillespie, 2008; Kaskie et al., 2008; Musick \& Wilson, 2008; Tang, 2006). In general, research suggests that women tend to be more involved in civic engagement activities (Adler, et al., 2007; Gottlieb \& Gillespie, 2008; Kaskie et al., 2008), though there is some evidence that men are more involved in informal volunteer activities than women (Zedlewski \& Schaner, 2006). In addition, age tends to be an important factor, particularly for volunteerism, as involvement tends to be higher among the young-old (Choi, 2003). Finally, those with higher education levels and individuals in better health are also more likely to be engaged (Adler, et al., 2007; Choi, 2003; Kaskie et al., 2008; Musick \& Wilson, 2008; Tang, 2006). In addition to these key predictors, research also suggests that social networks and social support play an important role in helping older adults learn about and participate in civic engagement opportunities (Choi \& Chou, 2010; Musick \& Wilson, 2008; Tang, 2006).

\section{Community/Social Group Participation}

Studies have found that participation in community and group activities can have a positive impact on older adults' mental health (e.g., Fiori, Antonucci, \& Cortina, 2006). 
Involvement in groups, clubs, or organizations is considered a source of bonding social capital (i.e., relations between people who share similar identities), and can provide an important source of social support and engagement for older adults (Poortinga, 2006). A study of bonding, bridging, and linking aspects of social capital found that civic participation in groups (in addition to measures of social cohesion, heterogeneous socioeconomic relationships, and political efficacy/trust) were significantly associated with individuals' self-reported health. This suggests that group participation is an important component to understanding links between social environments and health outcomes (Poortinga, 2012). Related to this, a study of a veteran's group members found that participation in the group's activities provided emotional support for members, and gave them an opportunity to engage in activities that were meaningful (Leedahl, Koenig, \& Ekerdt, 2011).

Studies focusing particularly on nursing homes have found that participation can be both beneficial for residents and provide a useful channel for improving the community within the nursing home. For example, in a quasi-experimental study of the effect of participation in a reminiscence group for twelve nursing home residents, Chao and colleagues (2006) found that participation in the group allowed the residents to increase their social interaction and provide peer support for other residents in the facility. In addition, in a study with seven residents in a Dutch nursing facility, Baur and Abma (2011) found that creation of and participation in a group provided the residents with the opportunity to influence and improve the quality of food and meal delivery in the nursing home. Finally, in a study evaluating the impact of participation in the design and implementation of a garden group at a nursing home, Raske (2010) found that participation provided residents with a meaningful activity that benefited the nursing home community and also increased opportunities for interaction among residents, family, and staff. 


\section{Resident Councils}

For many older adults, civic participation and activism are important ways to stay connected with and improve their communities (Adler, Schwarz, \& Kuskowski, 2007). For nursing home residents, participation in resident councils can provide an opportunity to engage with other residents and staff to address issues in their community (Devitt \& Checkoway, 1982; Meyer, 1991). In general, resident councils meet at regular intervals, act as a forum for identifying community issues, and share resident concerns with nursing home staff and administrators (Meyer, 1991). More specifically, as described in Wacker and Roberto (2014), resident councils provide residents the opportunity to provide input into the quality of care they receive and serve four key functions: 1) successfully advocating for modest changes in care (e.g., shower chairs, window blind adjustments); 2) providing assistance/services to residents and community members in need (e.g., making/selling handcrafted items, raising money); 3) expanding social activity opportunities (e.g., social outings to restaurants, planning ethnic and cultural menus); and 4) lobbying with resident councils from other nursing homes for quality of care improvements. While recent research on resident councils is limited, the findings from the Meyer (1991) study suggest that membership in resident councils is important to residents, to nursing homes, and to the community as a whole. However, these results also suggest that councils are only able to affect some small changes, and that more could be done to empower these groups (Baur \& Abma, 2011; O’Dwyer \& Timonen, 2010).

\section{Volunteerism}

Participation in formal volunteer activities has been associated with a number of benefits. For example, in a secondary data analysis of older adults from the Asset and Health Dynamics Among the Oldest Old Study (AHEAD), Lum and Lightfoot (2005) found that formal 
volunteering can act as a buffer, slowing down increases in functional limitations and depression. In addition, the authors found that volunteering reduced mortality rates. Harris and Thoresen (2005) similarly found that volunteering is associated with a reduced risk of mortality. More recently, findings from several studies of Experience Corps volunteer programs suggest that high-intensity volunteering is associated with improved physical and mental health (Barron, Tan, Yu, Song, McGill, \& Fried, 2009; Hong \& Morrow-Howell, 2010).

While informal volunteering, in comparison, has received much less attention, research suggests that older adults are more likely to engage in this form of volunteerism. For example, in a secondary data analysis study of non-institutionalized older adults in the Americans' Changing Lives Study, Hinterlong (2008) found that informal support and assistance to friends and neighbors was common form of civic engagement. Similarly, in a study of older adults in Baltimore, Martinez and colleagues (2011) found that participants in the study tended to think of volunteering as informal activities that helped their friends and neighbors.

\section{Voting}

Voting is a fundamental right and an important form of civic engagement for many older adults. However, research suggests that many nursing home residents often do not get the opportunity to vote (Bonnie, Freedman, \& Guterbock, 2013; Karlawish et al., 2008). This disenfranchisement may be due to logistical issues (e.g., transportation or registration issues), assumptions that residents are uninterested or incapable of voting, and/or a lack of social trust (Anderson, 2010; Bonnie et al., 2013; Karlawish et al., 2008; McEldowney \& Teaster, 2009). One study did find that most residents who vote in nursing homes (78.5\%) and assisted living facilities (58.9\%) fill out absentee ballots. Additionally, staff at nursing homes appear to be more active than staff at assisted living facilities in assisting with voter registration, filling out 
absentee ballots, and providing transportation to polling places on Election Day, and these activities are important for increasing voter participation (Bonnie et al., 2013). Logistical issues that can reduce opportunities for nursing home residents to vote include: a lack of understanding of procedures, lack of equipment such as computers, missed deadlines for absentee ballots, and/or an inadequate number of staff to assist residents. Staff may also wrongly assume that some residents are incapable of voting, particularly due to cognitive limitations (Bonnie et al., 2013; Karlawish et al., 2008). Finally, an individual's sense of community can influence their level of trust in others, and by extension, this can effect an individual's political participation (Anderson, 2010). However, it is uncertain if higher or lower trust influences greater political participation (Dyck, 2010).

This study expands our limited understanding of community and civic engagement participation among nursing home residents by describing older adult residents' participation in these four categories of community or civic engagement activities and examining factors that predict involvement among older adult residents. This study addresses two research questions: 1) What percent of nursing home residents in the sample are civically engaged (in four types of civic engagement: community/social group membership, resident council participation, informal volunteering within the facility, voting in a recent election)?

2) What demographic, health, and social integration variables predict involvement in four types of civic engagement activities for older adults in nursing homes?

\section{Methods}

\section{Recruitment and Participants}

We obtained a list of licensed nursing homes (i.e., nursing facilities) from the Kansas Department for Aging and Disability Services' Directory of Adult Care Homes. We targeted 78 
nursing homes in Northeast Kansas to limit the sample to nursing homes in areas with access to similar community resources and to ensure feasibility of data collection. We recruited a stratified, random sample of nursing homes within this targeted area by contacting nursing home administrators through an introductory letter and follow-up phone calls. The sample was stratified by large and smaller facilities in order to ensure adequate representation of nursing homes with degreed social workers on staff (i.e., larger facilities) and those not required to have degreed social workers on staff (i.e., smaller facilities), as social services have been shown to differ based on access to degreed social workers (Simons, Bern-Klug, \& An, 2012). The list of nursing homes was randomly ordered, and interviewers contacted administrators starting at the top of the list. If administrators approved study participation, they connected us with social service staff. The response rate for nursing homes was $38.9 \%(30 / 77)(47.4 \%$ of large facilities; $36.2 \%$ of smaller facilities), which is similar to other studies that have utilized nursing home samples (Simons \& Jankowski, 2008). Most nursing homes (83.3\%) were in semi-urban or urban counties, and about $15 \%$ were located in densely-settled rural and rural counties.

To obtain a random sample of nursing home residents, we worked with social service staff to identify residents eligible to participate in the study based on the inclusion criteria. These inclusion criteria were important to ensuring each resident was viewed as an older adult according to Medicaid guidelines (i.e., at least 65 years of age), was a long-term resident of the facility (i.e., lived there for more than four months), could personally consent to participation (i.e., did not have a legal guardian), and was cognitively able to answer the questions on the survey based on cognitive scores from the MDS. Once a list (with non-identifiable identification numbers) was generated, we randomly selected residents for social service staff to ask about participation in the study. We provided social service staff a recruitment script for discussing the 
study with residents and a permission form for residents to sign agreeing to have interviewers come to the nursing home. We worked with social service staff to schedule the interviews at times convenient for the residents. The overall response rate for residents was $75.7 \%(140 / 185)$. The University of Kansas Institutional Review Board (IRB) approved the sampling and data collection procedures, and further methodological details of the study can be found in Leedahl (in press).

\section{Survey}

Prior to gathering survey data, all interviewers took part in a training session and practiced the interview protocol. Then, we conducted in-person interviews using structured surveys with each resident participant. Participants were informed of the purpose of the study, their informed consent rights, and confidentiality issues. Interviewers recorded responses on the surveys, which included multiple standardized measures, and we employed a planned missing data design (i.e., three-form design) (see Graham, Taylor, Olchowski, \& Culsille, 2006 for full explanation) to ensure interviews did not take longer than one hour. Response choices were provided on laminated cards with extra-large print font to help participants in answering Likert scale questions. The survey was pilot tested at one nursing home to verify the length of the interviews (i.e., approximately one hour) and identify any question wording difficulties (e.g., minor revisions made). Participants were provided $\$ 20$ for participating in the study.

\section{Measures}

The dependent variables for this study included four types of civic engagement participation: community/social group membership, resident council participation, volunteering, and voting in a recent election. The civic engagement questions were asked as part of a broader set of questions related to social capital (e.g., Narayan and Cassidy, 2001) and social engagement 
(e.g., Glass, Mendes de Leon, Bassuk, \& Berkman, 2006; Jang, Mortimer, Haley, \& Borenstein Graves, 2004; Mitchell \& Kemp, 2000). Group membership was assessed by asking: how many groups or organizations do you belong to? We dichotomized the variable as: $1=$ those who listed 1 or more groups; $0=$ those who do not list any groups. We assessed for resident council participation and informal volunteering by asking how often they take part in these activities. The variables were dichotomized as: $1=$ participate/volunteer at least once a month; $0=$ does not or rarely participates/volunteers. Voting was assessed by asking how often they vote, and this was dichotomized as: $1=$ voted in a recent election; $0=$ has not voted within the past year. When asking about volunteering and group membership, interviewers asked residents to discuss their volunteer work and name the groups to which they belong, and they took notes on the responses. The independent variables consisted of predictor variables identified in the literature as potentially influencing civic engagement participation. The predictors included variables in the following categories: demographic (i.e., age, gender, education level); health (i.e., emotional well-being, activities of daily living (ADLs); and social integration (i.e., network size, social trust, social support). We did not include race/ethnicity as a demographic variable in this study due to low variation in responses (i.e., $92.7 \%$ of the sample identified as White/Caucasian).

Emotional well-being was assessed using the Geriatric Depression Scale (GDS), a 30item questionnaire in which participants are asked how they felt over the past week (Yesavage et al., 1983). This scale has been recommended for use with the nursing home population (Mitchell, Bird, Rizzo, \& Neader, 2010). We coded the GDS to indicate higher scores meant better emotional well-being (scoring for scale: 0-9= severe; 10-19= mild depression; 20-30= normal). The Cronbach's alpha for the GDS in this study was .86. ADLs were assessed using the Katz Index of Independence in Activities of Daily Living (Wallace \& Shelkey, 2008). This scale has 
been used with the nursing home population and can be assessed using self-report. We coded the variable to indicate that higher scores meant better function: 0 (very dependent) to 6 (independent). The Cronbach's alpha was .76.

Respondents named people in their social network using the concentric circle approach (Antonucci \& Akiyama, 1987), and network size was calculated by adding the total number of people named. Social trust was assessed using Likert scale questions about how much trust they had for ten different groups of people (e.g., people in your community, residents in the facility, staff in the facility, people in your family, local government, judges/police) (Narayan \& Cassidy, 2001; Norstrand \& Xu, 2012), and higher scores indicated greater trust. Cronbach's alpha for the trust measure was .79. Social support was assessed using a modified version of the Krause and Markides (1990) version of the widely used Inventory of Socially Supportive Behaviors (ISSB) (Barrera, Sandler, \& Ramsay, 1981). We used Likert scale questions about informational, tangible, and emotional support, and higher scores on the scale indicated more support. Cronbach's alpha for the social support measure was .90 .

\section{Analysis}

We conducted data imputation using multiple imputation in Mplus statistical software, and we conducted our analysis for this study using SPSS version 22 software. This study included eight predictor variables. Peduzzi, Concato, Kemper, Holford, and Feinstein (1996) suggest a minimum of 10 events/participants per variable when conducting logistic regression analysis. Therefore, with 139 participants in the sample, we are within the recommended guidelines. Descriptive statistics were first analyzed to understand how group membership/participation, resident council participation, volunteering, and voting varied by the predictor variables (i.e., demographic, health, social integration). Tolerance statistics indicated 
all variables were greater than .1, therefore multicollinearity was not an issue. We identified outliers by calculating Mahalanbois distance (Mertler \& Vannata, 2005). We identified one outlier (Mahalanobis distance greater than $x^{2}(8)=26.12$ ), which was removed from the analysis and resulted in the resident sample of 139. We examined relationships between the four types of civic engagement participation and predictor variables using bivariate analyses $(t$ tests for continuous variables and chi square tests for dichotomous variables). A series of binary logistic regression analyses were conducted to identify predictors of participation in the four types of civic engagement, and odds ratios (OR) and 95\% confidence intervals were calculated. We analyzed the answers to open-ended questions about volunteering and group membership via the interviewer notes on the survey forms using content analysis.

\section{Results}

First we report descriptive statistics for the demographic, health and social integration variables. The overall mean age for the sample was 83.2 (ranging from 65 to 103), and the majority was female (74.1\%). The average education level was 13 years, with a range from 6 years to 21 years. For emotional well-being, the mean for the GDS was 20.9, indicating average responses of normal to mild depression (scores ranged from 2 to 30, with higher scores indicating greater emotional well-being). For ADLs, the average score on the Katz Index was 3.2 indicating moderate to high levels of assistance required to meet activities of daily living (ranging from 0 to 6 , with higher scores indicating better function). The average network size for the residents was approximately 10 people, ranging from $0-30$. The average social trust score was 24.9 (ranging from 8-40, with higher scores indicating more trust), and the average social support scale score was 32.9 (ranging from 3-66, with higher scores indicating more support). 
Next we report descriptive statistics for the civic engagement variables as well as relevant findings from open-ended responses. For this sample of older adult nursing home residents with relatively high cognitive functioning, the most common civic engagement activity reported was group membership (67.6\%). Nearly half (48.9\%) reported resident council participation. Residents reported being a member of various organizations, including civic/community groups, church/religious groups, and within nursing home groups. Civic/community groups included: American Legion, League of Women Voters, Political Parties, Historical Society, Red Hat Society, Lion's Club, Hand Radio Operator Group, Knights of Columbus, Library of Friends, Cancer Action Organization, and Music Groups. Church/religious groups included various Christian churches (e.g., Catholic, Baptist, Lutheran), Jewish Temples, and bible study groups. Within nursing home groups included: Theatre Production Group, Grief Group, Choir, Resident Council, Bridge Group, Painting Group, Reading Group, and Exercise Group.

About one-quarter of the resident sample (26.6\%) reported volunteering within the facility. Residents reported a number of informal volunteer activities including: spending time with other residents who were sick or dying, assisting in the dining room, relaying concerns from other residents to the administration, reading daily news and announcements over the intercom, tending to a garden outside the nursing home, organizing a nursing home event with a scheduled speaker, creating collages for deceased residents' families, helping organize nursing home recycling efforts, and spending time with kids who visit the nursing home. Finally, nearly half $(46.8 \%)$ reported voting in a recent election.

After examining descriptive statistics, we compared the demographic, health, and social integration characteristics of those who participated in each civic engagement activity with those who did not. Table 1 includes the results for these bivariate analyses. For each of the activities 
(group membership, resident council participation, volunteering, and voting), resident participants were found to be younger than non-participants, but age was only significant for volunteering $(t=3.1, p<.01)$. A similar proportion of men and women reported taking part in the four types of civic engagement, and education levels between civic engagement participants and non-participants were quite similar, except for volunteering. Those who volunteered had about one more year of education than non-volunteers $(t=-1.9, p<.05)$. Those who reported higher levels of emotional well-being reported more civic engagement participation. As such, significant differences in emotional well-being were found for participants versus nonparticipants in group membership $(t=-2.6, p<.01)$ and resident council participation $(t=-2.8$, $p<.01$ ), and volunteering and voting differences approached significance. For volunteering, differences were identified regarding ADLs, with volunteers reporting better function than nonvolunteers $(t=-3.0, p<.01)$. Though seemingly civic engagement participants had approximately 1-2 more network members than non-participants, these differences were not significant. Differences in social trust scores were identified, showing that voters had lower social trust scores compared to non-voters $(t=2.2, p<.05)$. Finally, we identified significant differences in social support for group membership and resident council participation, with greater social support observed for group members $(t=-2.6, p<.05)$ and resident council participants $(t=-2.7$, $p<.01)$ compared to non-members/participants.

Insert Table 1 about here

To summarize the findings presented in Table 1, those with higher emotional well-being and greater social support reported more community/social group membership compared to nonmembers. Similarly, those who reported participating in resident council compared to those who did not reported better emotional well-being and greater social support. Residents who 
volunteered were younger, had higher levels of education, and higher ADL functioning. Finally, residents who voted had lower trust scores compared to those who had not recently voted.

Results from the logistic regression analyses are presented in Table 2, which estimate the odds of participating in the four types of civic engagement compared to non-participation. Similar to the results in Table 1, those who were younger were 9\% more likely to report volunteering (OR, 0.91, $p<.01)$, and individuals with fewer functional limitations (ADLs) were $47 \%$ more likely to volunteer $(\mathrm{OR}, 1.47, p<.01)$. Additionally, greater emotional well-being increased the odds of group membership by $7 \%(\mathrm{OR}, 1.07, p<.05)$ and of resident council participation by $9 \%(\mathrm{OR}, 1.09, p<.05)$. Greater social support increased the odds of group membership by $3 \%(\mathrm{OR}, 1.03, p<.05)$ and of resident council participation by $4 \%(\mathrm{OR}, 1.04$, $p<.05)$. Contrary to Table 1 findings, education did not predict volunteering, and social trust did not predict voting behavior, though both variables approached significance. Finally, nonsignificant predictors across all civic engagement types included gender, education, network size, and social trust.

\section{Insert Table 2 about here}

\section{Discussion}

This study investigated civic engagement participation among older adult nursing home residents and examined predictors of involvement in community/social groups, resident councils, volunteering, and voting. As this study shows, many residents can and do remain active, continuing or taking on new roles. In this sample of nursing home residents, the most common activity reported was membership in community/social groups, followed by resident council participation, voting in a recent election, and volunteering within the nursing home. Predictors of 
participation in civic engagement activities were to some extent consistent with findings for community dwelling older adults, with a few notable exceptions.

\section{Predictors of Participation}

Similar to previous research, this study found that mental health and social support predicted group membership and resident council participation. In addition, consistent with previous research, age and ADL function predicted volunteering, with younger and more physically able residents more likely to participate (Adler, Schwartz, \& Kuskoski, 2007; Choi, 2003; Gottlieb \& Gillespie, 2008; Kaskie et al., 2008; Musick \& Wilson, 2008; Tang, 2006). In contrast to previous research, social networks, gender, and education did not significantly predict civic engagement participation in this study. Aspects of the nursing home environment may help to explain some of these differences. For example, as the residents were already members of some of the community groups prior to living in the nursing home and the majority of the civic engagement activities in this study occurred in the nursing home, residents likely did not need a larger social network in order to learn about opportunities to participate. For gender, more men reported civic engagement than women in this study, which is in line with previous findings that men informally volunteer more than women (Zedlewski \& Schaner, 2006). However, because nursing homes tend to have greater proportions of women, detecting significant gender differences may be difficult. Finally, compared to those living in the community, residents in nursing homes tend to have less education (Kaye, Harrington, \& LaPlante, 2010), so again detecting differences may be more difficult in a nursing home population compared to a community-dwelling older adult population. 


\section{Community Group and Resident Council Participation}

In line with previous work suggesting that civic engagement not be exclusively focused on volunteerism (Anderson \& Dabelko-Schoeny, 2010; Martinez et al., 2011), our findings suggest there is potential for residents to get involved in and make meaningful contributions to their community in a variety of ways. An important point regarding this study's findings is that many residents reported membership in community and social groups of which they were once active members. At the time of the interview and while living in the nursing home, many may not have been current active participants in these organizations, but they did report being members of the groups. Therefore, community groups should recognize that these older adults still consider themselves members of the group, and that they could perhaps still contribute in meaningful ways.

Resident councils and other nursing home groups are essentially “community” groups within the nursing home, and residents take pride in their membership and participation in these groups. A study in the Netherlands suggested that nursing homes need to better support participation in resident councils (Baur \& Abma, 2011). In Ireland, it was found that resident councils did help to alleviate boredom for residents, but that nursing homes did little to encourage participation, empower residents, or overcome participation barriers (O’Dwyer \& Timonen, 2010). Due to the lack of recent research regarding resident councils, particularly in the United States, there is particular need for additional research on the current functions and benefits of resident councils and recognition of these groups as civic engagement. Studies of this nature could assist nursing homes and communities understand how to better support and utilize resident councils to meet increasing needs. 


\section{Volunteering}

This study is one of the first studies to include information on volunteerism of nursing home residents. We found that about one quarter of the nursing home residents in our sample were informally volunteering in nursing homes. Many of these opportunities were afforded to residents due to some creative thinking of nursing home staff regarding individual preferences and strengths. For example, at one nursing home, one resident read the daily news, weather, and announcements over the intercom each morning. She was contributing a valuable service to other residents and felt empowered to engage in the daily happenings of the nursing home community. In a discussion with an administrator about this topic, their staff indicated that even residents with cognitive impairment can volunteer, and that finding volunteer activities can help reduce difficult-to-manage behaviors, such as repeatedly asking for help with the same thing or wandering around in unsafe areas. These findings complement previous work by Martinez et al. (2011) that suggest older adults are motivated and interested in engaging in more civic activities, but that policies and practices need to be put in place that addresses barriers to participation and builds on individual motivations.

\section{Voting}

While Bonnie et al. (2013) identified that approximately $32 \%$ of all nursing home residents were registered to vote but only $15 \%$ actually cast a ballot, the higher voting rate among our sample (46.4\%) may be explained by the study requirements for high cognitive functioning. Further research should be done to evaluate voting rates based on cognitive status and establish best practices for assessing capacity to vote in order to maximize participation while also avoiding fraud and manipulation. 


\section{Study Limitations}

Due to the cross-sectional nature of the data, this study was not able to assess differences in civic engagement participation over time or establish causal relationships regarding civic engagement participation. Further, this sample included older adults with relatively high cognitive functioning. Therefore, this sample may only be representative of about $25 \%$ of older adults in nursing homes (Kaye, Harrington, \& LaPlante, 2010). This level of cognitive functioning was needed in order to ensure older adults could answer the questions, but this does provide limitations. We also acknowledge that our sample lacked in racial/ethnic diversity. Future work is needed to better understand civic engagement participation for older adults who have moderate to severe cognitive impairments and those of diverse racial/ethnic groups. As the study sample was limited to Kansas, this does limit the generalizability for the resident and the nursing home samples. However, we worked diligently to ensure random sampling of nursing homes and residents, so comparisons can be made to other areas that have similar geographic, institutional, or population characteristics. In a previous study, it was identified that there was no facility-level differences (i.e., multilevel variance) in the civic engagement variables (Leedahl, Chapin, \& Little, 2015), which helped justify the resident-level analyses used in the study. However as a limitation, this study was unable to account for multi-level factors that may influence civic engagement participation. Future work could examine civic engagement opportunities for residents and families across various nursing homes, and intervention work could evaluate civic engagement strategies across nursing homes and compare resident outcomes. 


\section{Implications}

This study's findings provide important new insights on civic engagement in nursing homes. Our findings have relevance for future practice, research, and policy decisions. Related to practice with older adults and in line with current culture change efforts in nursing homes, an expanded view of civic engagement could help community groups to implement new strategies to include resident involvement into their daily functions. For example, meetings held at nursing homes or assisted living facilities could ensure residents' participation, or small groups could come to the nursing home to execute various volunteer projects (e.g., putting together care packages, preparing mailings). Nursing home staff and family members could also help by identifying strategies to ensure active engagement among residents in these types of activities, such as using technology to help residents stay connected with social groups. Therefore, it is important that practitioners do not assume that residents are unable to participate. Developing strong relationships and a sense of community may also help residents stay engaged in civic activities. Future research should determine what supports and/or adaptations are needed to increase civic engagement related to group and resident council participation and formal volunteering among residents.

As suggested by Anderson and Dabelko-Schoeny (2010), it is important that nursing home residents are included in research related to civic engagement among older adults. This is needed to better understand predictors, examine outcomes of participation, and test identified best practices, such as using personal invitation, stipends, meaningfulness, and recognition (Sellon, 2014). Future research should include a qualitative study of nursing home residents, staff, and family members to identify creative ideas for how to engage residents in volunteer work and other civic activities. It would be helpful to learn about the types of volunteer activities 
individuals are engaged in, what additional activities individuals would like to do, and how nursing homes and families could support these efforts. The reality is that civic engagement could be inspiring for many older residents and give them hope and a sense of purpose while living in an environment that many consider their "last stop."

Furthermore, limiting discussions of civic engagement to formal volunteering and samples of community dwelling older adults ignores nursing home residents' contributions and limits the ability of practitioners to design appropriate programs. Because nursing homes are required to provide activity programs for each resident in order to enhance physical and mental health (Centers for Medicare and Medicaid Services (CMS), 2011), it is important that each resident has an individualized plan for activities based on their strengths and interests. To meet policy requirements, many nursing home residents could participate in activities that encourage civic engagement such as membership in clubs, serving on resident councils, volunteering, and voting.

Conceptually, Martinson and Minkler's (2006) discussion of civic engagement and older adults from a critical perspective is particularly relevant: "As gerontologists, we must continue to advocate for and develop programs and policies that promote an environment respectful of older people for who they are, not simply for what they can contribute. Such an environment would enable older people to live with dignity and to create their own meanings for later life. For some, that will include volunteer work and other forms of civic engagement. For others, it will not." (p. 323). It is not that civic engagement should be required (or even expected) of older adults, but rather those who are interested should be encouraged and enabled to take part in civic, volunteer, or other meaningful activities. As baby boomers age and need long term services and supports, facilities need to ensure residents can be engaged in activities beyond the "institutional wall" in 
order to maximize health and well-being and opportunities to engage in meaningful activities throughout the life course. 


\section{References}

Adler, G., Schwartz, J., \& Kuskowski, M. (2007). An exploratory study of older adults' participation in civic action. Clinical Gerontologist, 31(2), 65-75.

Adler, R. P., \& Goggin, J. (2005). What do we mean by “civic engagement”? Journal of Transformative Education, 3(3), 236-253.

Anderson, K., \& Dabelko-Schoeny, H. (2010). Civic engagement for nursing home residents: A call for social work action. Journal of Gerontological Social Work, 53(3), 270-282.

Anderson, M. (2010). Community psychology, political efficacy, and trust. Political Psychology, $31(1), 59-84$.

Antonucci, T.C., \& Akiyama, H. (1987). Social networks in adult life and a preliminary examination of the convoy model. Journal of Gerontology, 42(5), 519-527.

Barrera, M., Sandler, I.N., \& Ramsay, T.B. (1981). Preliminary development of a scale of social support: Studies on college students. American Journal of Community Psychology, 9, 435-447.

Barron, J. S., Tan, E. J., Yu, Q., Song, M., McGill, S., \& Fried, L. P. (2009). Potential for intensive volunteering to promote the health of older adults in fair health. Journal of Urban Health, 86(4), 641-653.

Baur, V. E., \& Abma, T. A. (2011). Resident councils between lifeworld and system: Is there room for communicative action? Journal of Aging Studies, 25(4), 390-396.

Bonnie, R. J., Freedman, P., \& Guterbock, T. M. (2013). Voting by senior citizens in long-term care facilities. Election Law Journal, 12(3), 293-304.

Bowling, A. (2007). Aspirations for older age in the $21^{\text {st }}$ century: What is successful aging? The International Journal of Aging and Human Development, 64(3), 263-297. 
Centers for Medicare \& Medicaid Services. (2011). State operations manual. Appendix PP guidance to surveyors for long term care facilities. (Rev. 70, 01-07-11). Retrieved on June 10, 2015 from http://www.cms.gov/Regulations-andGuidance/Guidance/Manuals/Internet-Only-Manuals-IOMs-Items/CMS1201984.html

Chao, S., Liu, H., Wu, C., Jin, S., Chu, T., Huang, T., \& Clark, M.J. (2006). The effects of group reminiscence therapy on depression, self esteem, and life satisfaction of elderly nursing home residents. Journal of Nursing Research, 14(1), 36-45.

Choi, L. H. (2003). Factors affecting volunteerism among older adults. Journal of Applied Gerontology, 22(2), 179-196.

Choi, N. G., \& Chou, R. J. A. (2010). Time and money volunteering among older adults: The relationship between past and current volunteering and correlates of change and stability. Ageing and Society, 30(4), 559-581.

Cnaan, R.A., Handy, F., \& Wadsworth, M. (1996). Defining who is a volunteer: Conceptual and empirical considerations. Nonprofit and Voluntary Sector Quarterly, 25(3), 364-383.

Cullinane, P. (2006). Late-life civic engagement enhances health for individuals and communities. The Journal on Active Aging, 5(6), 66-73.

Dabelko-Schoeny, H., Anderson, K.A., \& Spinks, K. (2010). Civic engagement for older adults with functional limitations: Piloting an intervention for adult day health participants. The Gerontologist, 50(5), 694-701.

Dai, B., Zhang, B., \& Li, J. (2013). Protective factors for subjective well-being in Chinese older adults: The roles of resources and activity. Journal of Happiness Studies, 14, 1225-1239.

Devitt, M., \& Checkoway, B. (1982). Participation in nursing home resident councils: Promise and practice. The Gerontologist, 22(1), 49-53. 
Dyck, J.J. (2010). Political distrust and conservative voting in ballot measure elections. Political Research Quarterly, 63(3), 612-626.

Estes, C. (2001). Social policy and aging: A critical perspective. Thousand Oaks, CA: Sage Publications.

Finchum, T., \& Weber, J.A. (2000). Applying continuity theory to elder adult friendships. Journal of Aging \& Identity, 5(3), 159-168.

Fiori, K.L., Antonucci, T.C., \& Cortina, K.S. (2006). Social network typologies and mental health among older adults. Journals of Gerontology Psychological and Social Sciences, 61, P25-P32.

Gammonley, D. (2009). Psychological well-being and social support among elders employed as lay helpers. Journal of Gerontological Social Work, 52(1), 64-80.

Glass, T.A., Mendes de Leon, C.F., Bassuk, S.S., \& Berkman, L.F. (2006). Social engagement and depressive symptoms in late life. Journal of Aging and Health, 18(4), 604-628.

Graham, J.W., Taylor, B.J., Olchowski, A.E., \& Cumsille, P.E. (2006). Planned missing data designs in psychological research. Psychological Methods, 11(4), 323-343.

Greenfield, E. A., \& Marks, N. F. (2004). Formal volunteering as a protective factor for older adults' psychological well-being. The Journals of Gerontology Series B: Psychological Sciences and Social Sciences, 59(5), S258-S264.

Harris, A. H., \& Thoresen, C. E. (2005). Volunteering is associated with delayed mortality in older people: Analysis of the longitudinal study of aging. Journal of Health Psychology, 10(6), 739-752. 
Havighurst, R., \& Albrecht, R. (1953). Older people. New York, NY: Longmans, Green.

Hinterlong, J. E. (2008). Productive engagement among older Americans: Prevalence, patterns, and implications for public policy. Journal of Aging \& Social Policy, 20(2), 141-164.

Hong, S. I., \& Morrow-Howell, N. (2010). Health outcomes of Experience Corps ${ }^{\circledR}$ : A highcommitment volunteer program. Social Science \& Medicine, 71(2), 414-420.

Hooyman, N. R., \& Kiyak, H. A. (2011). Social gerontology: A multidisciplinary perspective. Boston, MA: Allyn \& Bacon.

Jang, Y., Mortimer, J.A., Haley, W.E., \& Borenstein Graves, A.R. (2004). The role of social engagement in life satisfaction: Its significance among older individuals with disease and disability. Journal of Applied Gerontology, 23(3), 266-278.

Johnson, J.D., Whitlach, C.J., \& Menne, H.L. (2014). Activity and well-being of older adults, Does cognitive impairment play a role? Research on Aging, 36(2), 147-160.

Karlawish, J.H.T., Bonnie, R.J., Appelbaum, P.S., Kane, R.A., Lyketsos, C.G., Karlan, P. ... \& Knopman, D. (2008). Identifying the barriers and challenges to voting by residents in nursing homes and assisted living settings. Journal of Aging \& Social Policy, 20(1), $65-$ 79.

Kaskie, B., Imhof, S., Cavanaugh, J., \& Culp, K. (2008). Civic engagement as a retirement role for aging Americans. The Gerontologist, 48(3), 368-377.

Kaye, H.S., Harrington, C., \& LaPlante, M.P. (2010). Long-term care: Who gets it, who provides it, who pays, and how much? Health Affairs, 29(1), 11-21.

Krause, N., \& Markides, K.S. (1990). Measuring social support among older adults. International Journal of Aging and Human Development, 30(1), 37-53.

Leedahl, S.N., Chapin, R.K., \& Little, T.D. (2015). Multilevel examination of facility 
characteristics, social integration, and health for older adults living in nursing homes. Journals of Gerontology, Series B: Psychological and Social Sciences, 70(1), 111-122.

Leedahl, S.N., Koenig, T.L., \& Ekerdt, D.J. (2011). Perceived benefits of VFW post participation for older adults. Journal of Gerontological Social Work, 54(7), 712-730.

Leedahl, S.N. (in press). Successfully collecting quantitative data from random samples of nursing homes \& residents. SAGE Research Methods Cases.

Lum, T. Y., \& Lightfoot, E. (2005). The effects of volunteering on the physical and mental health of older people. Research on Aging, 27(1), 31-55.

Martinez, I., Crooks, D., Kim, K. S., \& Tanner, E. (2011). Invisible civic engagement among older adults: Valuing the contributions of informal volunteering. Journal of Cross Cultural Gerontology, 26. 23-27.

Martinez, I. L., Frick, K., Glass, T. A., Carlson, M., Tanner, E., Ricks, M., \& Fried, L. P. (2006). Engaging older adults in high impact volunteering that enhances health: recruitment and retention in the Experience Corps ${ }^{\circledR}$ Baltimore. Journal of Urban Health, 83(5), 941-953.

Martinson, M., \& Minkler, M. (2006). Civic engagement and older adults: A critical perspective. The Gerontologist, 46(3). 318-324.

McEldowney, R., \& Teaster, P.B. (2009). Land of the free, home of the brave: Voting accommodations for older adults. Journal of Aging \& Social Policy, 21(2), 159-171.

Mertler, C. A., \& Vannatta, R. A. (2005). Advanced and multivariate statistical methods: Practical application and interpretation (3rd ed.). Los Angeles, CA: Pyrczak.

Meyer, M. D. (1991). Assuring quality of care: Nursing home resident councils. Journal of Applied Gerontology, 10(1), 103-116.

Mitchell, A.J., Bird, V., Rizzo, M., \& Neader, M. (2010). Which version of the Geriatric 
Depression Scale is most useful in medical settings and in nursing homes? Diagnostic validity meta-analysis. American Journal of Geriatric Psychiatry, 18(12), 1066-1077.

Mitchell, J.M., \& Kemp, B.J. (2000). Quality of life in assisted living homes: A multi-dimension analysis. Journal of Gerontology: Psychological Sciences, 55B(2), P117-P127.

Morrow-Howell, N. (2010). Volunteering in later life: Research frontiers. The Journals of Gerontology Series B: Psychological Sciences and Social Sciences, 65(4), 461-469.

Morrow-Howell, N., Hinterlong, J., Rozario, P. A., \& Tang, F. (2003). Effects of volunteering on the well-being of older adults. The Journals of Gerontology Series B: Psychological Sciences and Social Sciences, 58(3), S137-S145.

Morrow-Howell, N., Hong, S. I., \& Tang, F. (2009). Who benefits from volunteering? Variations in perceived benefits. The Gerontologist, 49(1), 91-102.

Mui, A. C., Glajchen, M., Chen, H., \& Sun, J. (2013). Developing an older adult volunteer program in a New York Chinese community: An evidence-based approach. Ageing International, 38(2), 108-121.

Musick, M. A., \& Wilson, J. (2008). Volunteers: A social profile. Bloomington, IN: Indiana University Press.

Narayan, D., \& Cassidy, M.F. (2001). A dimensional approach to measuring social capital: Development and validation of a social capital inventory. Current Sociology, 49, 59-102.

Norstrand, J.A., \& Xu, Q. (2012). Social capital and health outcomes among older adults in China: The urban-rural dimension. The Gerontologist, 52(3), 325-334.

O'Dwyer, C., \& Timonen, V. (2010). Rethinking the value of residents' councils: Observations and lessons from an exploratory study. Journal of Applied Gerontology, 29(6), 762-771. 
O’Neill, G. (2006-2007). Civic engagement on the agenda at the 2005 White House Conference on Aging. Generations, 30, 95-100.

Peduzzi, P., Concato, J., Kemper, E., Holford, T.R., \& Feinstein, A.R. (1996). A simulation study of the number of events per variable in logistic regression analysis. Journal of Clinical Epidemiology, 49(12), 1373-1379.

Poortinga, W. (2006). Social relations or social capital? Individual and community health effects of bonding social capital. Social Science \& Medicine, 63, 255-270.

Poortinga, W. (2012). Community resilience and health: The role of bonding, bridging, and linking aspects of social capital. Health \& Place, 18(2), 286-295.

Raske, M. (2010). Nursing home quality of life: Study of an enabling garden. Journal of Gerontological Social Work, 53(4), 336-351.

Rice, S. (1989). Single, older childless women: Differences between never-married and widowed women in life satisfaction and social support. Journal of Gerontological Social Work, $13(3 / 4), 35-47$.

Sellon, A.M. (2014). Recruiting and retaining older adults in volunteer programs: Best practices and next steps. Ageing International, 39(4), 421-437.

Siebert, D.C., Mutran, E.J., \& Reitzes, D.C. (1999). Friendship and social support: The importance of role identity to older adults. Social Work, 44(6), 522-533.

Simons, K., Bern-Klug, M., \& An, S. (2012). Envisioning quality psychosocial care in nursing homes: The role of social work. Journal of the American Medical Directors Association, $13,800-805$.

Simons, K.V., \& Jankowski, T.B. (2008). Factors influencing nursing home social workers' intentions to quite employment. Administration in Social Work, 32(1), 5-21. 
Tang, F. (2006). What resources are needed for volunteerism? A life course perspective. Journal of Applied Gerontology, 25(5), 375-390.

Turner, R. H. (1978). The role and the person. American Journal of Sociology, 84(1), 1-23.

Wacker, R. R., \& Roberto, K. A. (2014). Community resources for older adults: Programs and services in an era of change. Los Angeles, CA: Sage.

Wallace, M., \& Shelkey, M. (2008). Monitoring functional status in hospitalized older adults, The Katz Index of Independence in Activities of Daily Living can help nurses detect subtle changes in health and prevent functional decline. American Journal of Nursing, 108(4), 4-71.

White House Conference on Aging. (2015). Final report. Retrieved on March 24, 2016 from http://archive.whitehouseconferenceonaging.gov/

World Health Organization. (2015). World report on ageing and health. Retrieved on March 25, 2016 from http://www.who.int/ageing/publications/world-report-2015/en/

Yesavage, J. A., Brink, T. L., Rose, T. L., Lum, O., Huang, V., Adey, M., \& Leirer, V. (1983). Development and validation of a Geriatric Depression Screening Scale: A preliminary report. Journal of Psychiatric Research, 17, 37-49.

Zedlewski, S.R., \& Schaner, S.G. (2006). The retirement project: Perspectives on productive aging. Urban Institute Policy Brief. Retrieved on October 5, 2015 from http://www.urban.org/research/publication/older-adults-engaged-volunteers 